\title{
Cellular processing determinants for the activation of damage signals in response to topoisomerase I-linked DNA breakage
}

\author{
Ting-Hsiang Huang ${ }^{1}$, Hsiang-Chin Chen ${ }^{1}$, Shang-Min Chou ${ }^{1}$, Yu-Chen Yang ${ }^{1}$, Jia-Rong Fan ${ }^{1}$, Tsai-Kun Li ${ }^{1}$ \\ ${ }^{\prime}$ Department and Graduate Institute of Microbiology, College of Medicine, National Taiwan University, No. 1, Section 1, Jen-Ai \\ Road, Taipei 10018
}

Recent studies have suggested an involvement of processing pathways for the initiation of cellular responses induced by topoisomerase-targeting drugs. Here, we showed that cellular exposure to camptothecin (CPT) induced formation of topoisomerase I cleavable complex (TOP1cc), degradation of TOP1 and activation of DNA damage responses (DDR). Transcription and proteasome-dependent proteolysis, but not replication, were involved in CPTinduced TOP1 degradation, while none of above three processing activities affected TOP1cc formation. $\underline{\text { Replication- }}$ and transcription-initiated processing (RIP and TIP) of TOP1ce were identified as two independent pathways, which contribute distinctly to various CPT-activated DDR. Specifically, in cycling cells, RIP-processed TOP1cc triggered the CPT-induced RPA phosphorylation. At higher CPT dosages, the TIP pathway is required for other DDR activation, including ATM, p53 and Chk1/2 phosphorylation. The TIP pathway was further demonstrated to be S-phase independent by using three nonreplicating cell models. Furthermore, the effect of proteasome inhibitors mimicked that of transcription inhibition on the CPT-induced activation of DDR, suggesting the involvement of proteasome in the TIP pathway. Interestingly, the TIP pathway was important for TOP1cc-activated, but not ionization radiationactivated ATM, p53 and Chk2 phosphorylation. We have also found that pharmacological interferences of TIP and RIP pathways distinctively modulated the CPT-induced cell killing with treatments at low and high dosages, respectively. Together, our results support that both RIP and TIP pathways of TOP1cc are required for the activation of CPT-induced DDR and cytotoxicity.

Keywords: cleavable complex; processing; downregulation; protein-linked DNA break; DNA damage responses Cell Research (2010) 20:1060-1075. doi:10.1038/cr.2010.95; published online 6 July 2010

\section{Introduction}

Genomic DNA damage, through activation and coordinative effects of signaling molecules, is critically involved in carcinogenesis, neuron degeneration, aging, as well as tumor cell killing by chemotherapeutic agents [1-3]. DNA damage responses (DDR) involve a series of protein factors functioning in damage processing and detection, activation of checkpoint and repair pathways,

Correspondence: Tsai-Kun Li

Tel: +886 223123456, ext. 88287/88294; Fax: +886 223915293

E-mail: tsaikunli@ntu.edu.tw

Received 10 October 2009; revised 13 January 2010; accepted 2 April

2010; published online 6 July 2010 as well as the resumption of normal cellular activities after damage has been repaired [1, 3, 4]. These DDR also play important roles in both DNA damage-induced genome instability and cytotoxicity. Therefore, knowledge of DDR activation might serve as a potential pharmacological intervention strategy [1-4]. Recently, proteinlinked DNA breakage has also been considered as a threat to genome integrity and cell survival [4-7]. The best example of this is topoisomerase cleavable complex (TOPcc) induced by their targeting drugs, such as camptothecin (CPT) and etoposide (VP-16) [4-7]. Taking CPT for an example, it acts solely by stabilization of topoisomerase I cleavable complex (TOP1cc), in which TOP1 is covalently linked to the $3^{\prime}$-end of broken DNA, which also leads to the subsequent activation of DDR $[4,6]$. However, the underlying mechanism(s) and processes by 
which TOP1cc activates DDR remain largely undefined.

The crystal structure of TOP1cc reveals that the enzyme wraps around DNA duplex with the DNA-linking tyrosine residue in TOP1 protein center [8-10], suggesting that TOP1-linked DNA breakage in the TOP1cc might exist as a hidden DNA break. The structural information [8-10] and recent studies on the roles of cellular activities and pathways for TOPcc-induced DDR [1116] have suggested that the interactions between TOPcc and cellular activities, such as proteasomal degradation, might process DNA break embedded in the enzyme center into more detectable DNA lesions. These DNA lesions are differentially detected and then followed by the activation of various DDR. Moreover, these cellular activities have also been identified as important cytotoxic determinants for topoisomerase-targeting drugs $[4,6$, 14]. Taken together, these results suggest cellular processing of protein-capped DNA breakage (for example, proteolytic removal of enzyme from TOPcc) as a prerequisite for the subsequent DDR activation. Using the etoposide-induced TOP2cc, where TOP2s are covalently linked to the $5^{\prime}$ terminus of DNA break, as the model molecule, our group has shown that helical tracking processes and 26S proteasome are critically involved in the processing of TOP $2 \mathrm{cc}$ into different forms of DNA lesions. Two independent pathways, transcription- and replication-initiated processing (TIP and RIP), of TOP2cc have been defined. We have further shown that these two pathways play distinctive roles in the activation of etoposide-induced DDR and signaling [14]. Notably, cellular activities in the TOP2cc-processing pathways have also been shown to be involved in converting TOP1cc into different forms of DNA lesions [12, 13, 17-21]. Different from that of TOP2cc, TOP1 is linked covalently to the $3^{\prime}$ terminus of DNA single-stranded break (SSB) in TOP1cc. We thus proposed that TIP and RIP pathways are likely involved in the processing of TOP1cc into different forms of detectable DNA lesions, subsequently leading to distinctive activation of corresponding DDR.

Literature reports further suggest that replication (that is, the RIP pathway) is closely related to several CPTactivated DDR, including RPA phosphorylation, NF- $\kappa B$ activation and the Rad52 double-stranded break (DSB) repair pathway, as well as stabilization of $\mathrm{p} 53$ protein [4-6, 21]. In addition, studies have also suggested other potential TOP1cc-processing activities and pathways, such as transcription, helicases, tyrosyl-DNA phosphodiesterase Tdp1 and ubiquitin-proteasome pathway (UPP) [4-6]. It has been shown that TOP1cc, located on the template strand within the transcribed region, was found to be converted into irreversible strand breaks by the elongating RNA polymerase in an in vitro assay sys- tem. The UPP pathway and Tdp1 have been shown to be involved in the removal of TOP1 from enzyme-linked DNA breaks. Owing to the ability in removal of enzyme from cleavable complex, the UPP pathway and Tdp1 have thus been suggested to participate in the repair of TOP1- and/or TOP2-linked DNA breaks [6, 12-15]. In addition, the CPT-induced degradation of TOP1 (namely TOP1 downregulation) is initiated by the collision between RNA polymerase and TOP1cc, followed by proteolysis through the UPP pathway, like those observed in the process of TOP2cc downregulation [4, 14, 22, 23]. We thus sought to determine the potential involvement(s) of TOP1cc-processing activities in the TOP1cc-activated DDR.

In the current study, we have investigated the involvement of replication, transcription and proteasome-mediated proteolysis in different processing pathways (TIP and RIP) of TOP1cc, as well as their distinct contributions to the CPT-induced activation of DNA damage signals and subsequent cell killing. CPT was used to induce TOP1cc formation, TOP1 downregulation, DDR activation and cell killing. First, we found that all three cellular processing activities did not contribute to the CPT-induced TOP1cc formation. However, blockage of the TIP pathway through inhibition of transcription and proteasome reduced the CPT-induced TOP 1 downregulation and comet tail moment. Using the in vivo complex of enzyme (ICE) bioassay and the TOP1 downregulation assay, we observed that TOP1 proteins in the fraction of TOP1cc were degraded in response to CPT treatment. This degradation of TOP1cc could be relieved by cotreatment only with inhibitors of the TIP pathway, but not with the RIP inhibitor, aphidicolin (APH). Next, we investigated the involvement of TIP and RIP pathways in the activation of CPT-induced DDR and found that RPA phosphorylation was mainly initiated through the RIP pathway of TOP1cc, as previously reported [21]. The involvement of RIP pathway in the activation of CPT-induced DDR is supported by a recent study showing the role of TOP1cc-mediated and replication-dependent DNA DSBs in the CPT-induced $\gamma$-H2AX activation [12]. Nevertheless, several DDR activations, including $\gamma$-H2AX, ATM and Chk2 phosphorylation, have also been observed in nonreplicating, post-mitotic cells treated with CPT [11], suggesting a replication-independent mechanism for the activation of CPT-induced DDR. Consistent with the above notion, we demonstrated that the CPT-induced activation of ATM, p53 and Chk2 required the TIP pathway of TOP1cc. To our surprise, the CPT-activated phosphorylation of ATM, Chk2 and p53, unlike that of RPA, were affected by replication inhibition (blockage of the RIP pathway) only at low-dose CPT treatments. 
These results suggested that the activation mechanisms for the TOP1cc-induced DDR in response to low and high dosage of CPT treatments might be different. The novel TIP requirement of TOP1cc for the activation of ATM, Chk2 and p53 has been further demonstrated using three nonreplicating cell systems, including APH-treated HCT116 cells, quiescent MRC-5 primary fibroblasts and murine resting B cells. Interestingly, we have also found that CPT-induced cell killing at low and higher dosages was compromised by inhibition of the RIP pathway and blockage of the TIP pathway, respectively. Addition of TIP and RIP inhibitors did not affect the ionization radiation (IR)-induced DDR activation, suggesting that these two processing pathways are for TOP1cc. Collectively, these results support a TIP-associated model where both transcription collision of TOP1cc and subsequent proteasomal degradation of TOP1cc contribute to the uncapping of TOP1-linked DNA break and the activation of downstream DDR in cells treated with CPT.

\section{Results}

Cellular exposure to CPT results in generation of TOP1linked DNA breaks on chromosomes of HCT116 colorectal cancer cells

CPT treatment has been shown to induce the formation of TOP1cc and subsequent activation of signaling molecules and corresponding DDR [11-13]. We first used the alkaline comet assay to detect DNA SSBs induced by CPT treatment and to characterize the reversibility of these breaks. In Figure 1A, exposure to CPT $(1 / 2 \mathrm{~h})$ caused dose-dependent DNA breaks in HCT116 colon cancer cells (\% indicates the percentage of cells with DNA breaks), and these SSBs were highly reversible after 30 min of medium reversal (compare panels $\mathrm{E}$ to $\mathrm{H}$ and F to I, Figure 1A). Next, covalent-linked complexes of TOP1 with DNA (TOP1cc) were also observed in the CPT-treated cells, as indicated by the disappearance of free TOP1 in the trapping assay (Figure 1B) and the presence of TOP1 proteins in the DNA fractions of the ICE bioassay (Figure 1C). In the trapping assay, only the free form TOP1 is detectable. Enzymes in the form of TOP1cc remain covalently linked to / trapped on chromatin and thus are not detectable. In the ICE bioassay, TOP 1 proteins in both TOP $1 \mathrm{cc}$ and free form can be detected $[5,24]$. Due to their differences in density, proteins and DNA are partitioned into different fractions in this equilibrium gradient analysis, achieving a separation of TOP1 proteins in the DNA-free form and the DNAlinked form (that is, TOP1cc) [25]. As shown in Figure $1 \mathrm{C}$ (top, '-' panel), TOP1 proteins and DNA partitioned mostly in fractions 1-4 and factions 5-8 (picked at frac- tion 6 , as measured by $\mathrm{OD}_{260}$ ), respectively. TOP1 proteins in the DNA-containing fractions (that is, TOP1cc) only appeared after CPT treatment $(10 \mu \mathrm{M}, 1 / 2 \mathrm{~h})$. After $4 \mathrm{~h}$ of CPT treatment, it appeared that TOP1 proteins in both free and TOP1cc form were decreased. The degradation of TOP1 in the form of TOP1cc (especially in the fraction no 7) was thus suggested. By analyzing the CPTinduced comet tail moment, we have also determined and shown the extent of DNA breaks on different dosages of CPT treatment (Figure 1D). This quantitative approach further showed that the level of TOP1 covalently trapping on chromatin (by the trapping assay) and the extent of DNA breaks (by the comet assay) are positively correlated. We concluded that cellular exposure to CPT efficiently induces TOP1cc/TOP1-linked DNA breakage in HCT116 cells.

\section{CPT-induced DNA breakage is reversible and covalently linked with proteins}

To further support the above notion that TOP1 in the form of TOP1cc indeed covalently links with DNA, S7 nucleases were used to release trapped TOP1 from DNA. As revealed in Figure 1E, the level of free TOP1 in the S7 nuclease-digested, CPT-treated extract ( $\sim 90.3 \%$; lane 4) was much higher than that of the undigested one $(\sim$ $31.6 \%$; compare lane 2 to 4$)$. The reversible nature of TOP1cc was further supported by the observation that the percentage of trapped TOP1cc was greatly reduced after an additional medium reversal (compare lane 2 to 6; Figure 1E). Since the broken end of TOP1-mediated DNA break (TOP1cc) is covalently linked to the tyrosine residue in the enzyme center and the X-ray crystal structure analyses of TOP1 in both covalent and noncovalent complexes have also revealed that TOP1 protein wraps around DNA duplex [8-10], we therefore suggested that the CPT-induced DNA break in TOP1cc is likely wrapped by TOP1 protein and might need cellular activities to process it into detectable DNA lesions.

\section{Downregulation of TOP1 in TOP1cc on CPT treatment in both normal and cancer cells}

Results from our and other groups suggest that TOP1 is downregulated on CPT treatment $[12,13,22]$. Consistently, we have observed that TOP1 proteins in HCT116 cells were degraded after $10 \mu \mathrm{M}$ CPT treatment in a time-dependent manner (Figure 2A). As stated above (Figure 1C; the ICE bioassay), we have found that TOP1 degradation after CPT treatment also occurred in the fractions of TOP1cc, which is similar to that observed for the etoposide-induced degradation of TOP2 [14]. We have also observed the differential downregulation of TOP1 responding to CPT treatment in ZR75-1and 
BT474 breast cancer cells (Figure 2B) as reported [23]. In addition, CPT induced efficient TOP1 downregulation in both actively growing and quiescent MRC-5 primary fibroblasts (compare lane 2 to 5 or 3 to 6; Figure 2C), despite the lower level of TOP1 proteins in the quiescent cells ( $\sim 84.5 \%$ of that in actively growing cells). These results together suggest the potential role of proteolytic degradation of TOP1 in the processing of TOP1cc.
TOP1 downregulation depends on active transcription and proteasome pathway

Next, we sought to further study the potential role of processing pathway(s) of TOP1cc in the activation of CPT-induced DDR. First, serum starvation was used to arrest MRC-5 primary cells in G0 quiescent phase of cell cycle where DNA replication is ceased [26]. Cultivation of human primary cells in $0.1 \%$ of serum for $72 \mathrm{~h}$ re-
A

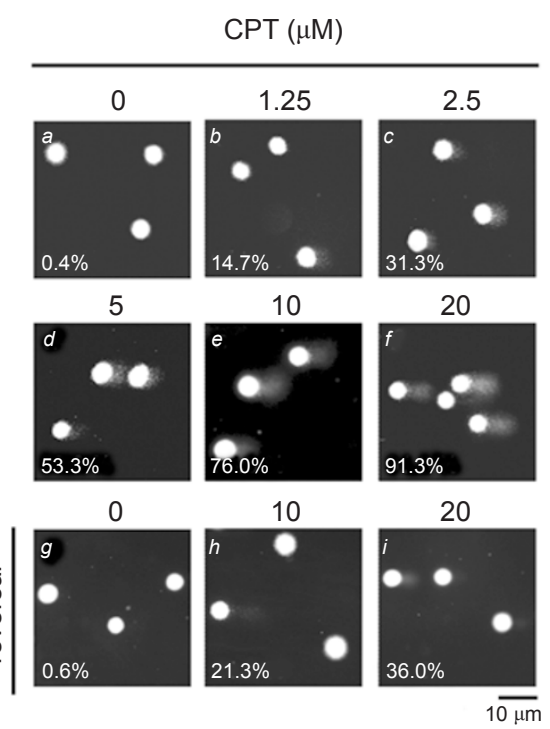

D

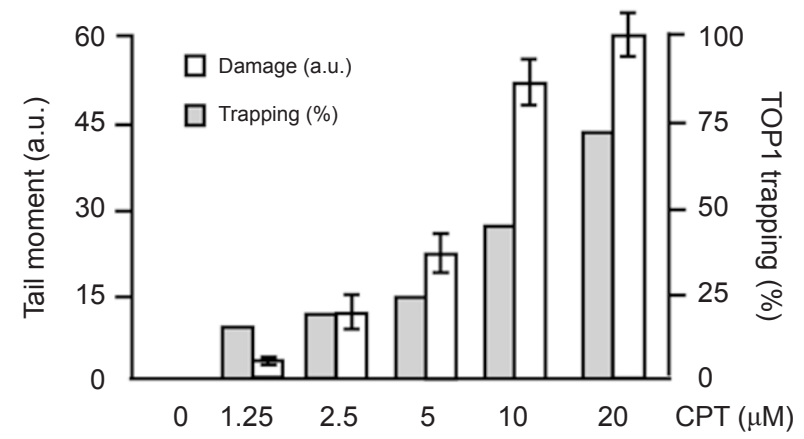

B

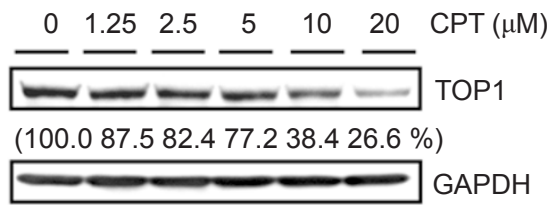

C

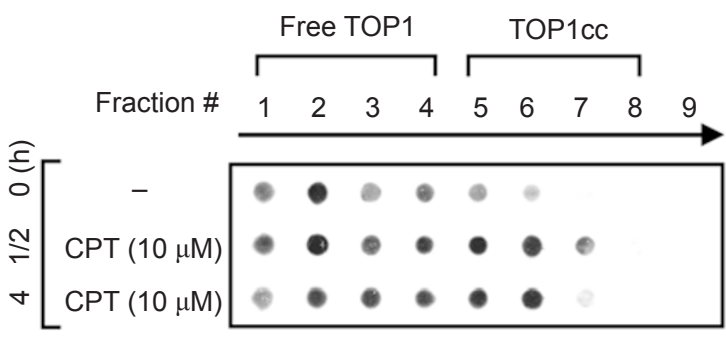

$E$

Figure 1 Cellular exposure to CPT results in the formation of reversible TOP1-linked DNA breaks. (A) The comet assay revealed an induction of reversible and dose-dependent DNA strand breaks on chromosome DNA on CPT treatment. Values (\%) indicated at the bottom of each panel represent the percentage of cells with comet tail after different treatments. CPT treatment caused TOP1 trapping on chromatin, as revealed by the trapping assay (B) and the ICE bioassay (C). The values (\%) indicate the percentage of un-trapped/free TOP1 in cells exposed to different dosages of CPT. (D) A positive correlation between the level of DNA breaks and the extent of TOP1 trapped on DNA after CPT treatment. (E) TOP1 trapped in the form of TOP1 cleavable complex (TOP1cc) is also highly reversible and can be released by an additional treatment of S7 DNA nucleases. The values of percentage (\%) represent the un-trapped TOP1, as described in B. HCT116 $\left(\sim 2 \times 10^{5}\right)$ cells were treated with CPT (concentrations as indicated in $\mu \mathrm{M}$ ) for $1 / 2 \mathrm{~h}$ and then assays for TOP1-linked DNA breaks were performed as described in the "Material and Methods". The extent of comet tail moment (that is, the level of DNA breaks, A) and the percentage of free TOP1 (\%, B, E) in response to CPT treatment were analyzed and are shown in corresponding panels. GAPDH is used as the normalization control for loading. a.u.: arbitrary units. 
A

B

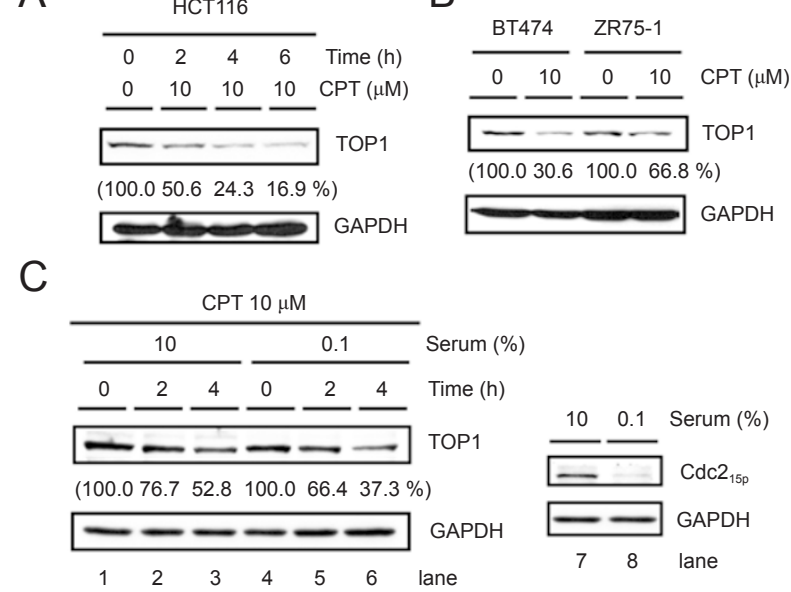

$\mathrm{D}$

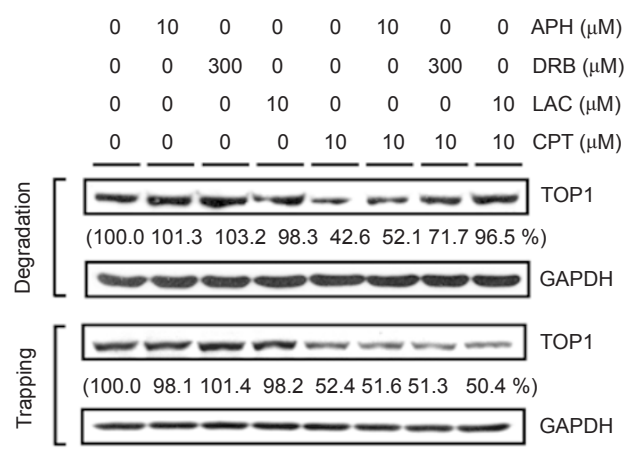

Figure 2 CPT treatment induces differential TOP1 downregulation in primary and cancer cell lines. (A) TOP1 proteins were efficiently degraded after CPT treatment in a time-dependent manner in HCT116 colorectal cancer cells. (B) Differential degradation of TOP1 in BT474 and ZR75-1 breast cancer cells. (C) CPT induced similar TOP1 downregulation in actively growing $(10 \%$ serum $)$ and quiescent $(0.1 \%$ serum $)$ primary MRC5 fibroblasts. (D) The CPT-induced downregulation of TOP1, but not formation of TOP1cc, depends on active transcription and proteasome. Values (\%, A-D) indicate the percentage of un-degraded and/or free TOP1 in treated cells. Cells were first pretreated with or without inhibitors $(\mu \mathrm{M})$ for $1 / 2 \mathrm{~h}$. Cells were then cotreated with $10 \mu \mathrm{M}$ CPT for $1 / 2 \mathrm{~h}$ for the trapping assay and 2-6 $\mathrm{h}$ for the TOP1 downregulation assay. APH, aphidicolin; DRB, 5, 6-dichlorobenzimidazole riboside; LAC, lactacystin.

sulted in loss of Tyr15 phosphorylation of Cdc2 ( $\left.\mathrm{Cdc} 2_{15 \mathrm{p}}\right)$ (compare lane 7 to 8; Figure 2C), which is a S-phase indicator [26]. The fact that TOP1 downregulation was not compromised in the quiescent cells was also in agreement with the notion that replication is not involved in the CPT-induced TOP1 downregulation. Next, pharmacological inhibitors were used to examine cellular activities involved in the TOP1 downregulation. The inhibition of replication by APH and transcription by 5, 6-dichlo- robenzimidazole riboside (DRB) was determined by the uptake or incorporation assay (Supplementary information, Figure S1A and data not shown). APH blocked DNA replication effectively $(86.5 \pm 3.5 \%$ at $1 \mu \mathrm{M})$, with almost no inhibition on RNA transcription, while DRB preferentially inhibited more transcription $(76.0 \pm 1.0 \%$ at $300 \mu \mathrm{M})$ than replication $(55.5 \pm 1.5 \%$ at $300 \mu \mathrm{M})$. As reported [12, 22], inhibition of DNA synthesis had only minimal effect on TOP1 downregulation. However, TOP1 downregulation was greatly compromised in the presence of transcription inhibitor DRB or proteasome inhibitor lactacystin (LAC) (Figure 2D, upper panel). Other proteasome inhibitors, Bortezomib (Velcade) and MG132, also blocked CPT-caused TOP1 degradation at 0.15 and $1 \mu \mathrm{M}$, respectively (data not shown). TOP1 downregulation blocked by transcription or proteasome inhibition is not due to their potential interference on the formation of TOP1cc, since none of inhibitors affected the CPT-induced TOP1 trapping on chromatin (Figure $2 \mathrm{D}$, lower panel). We therefore reasoned that, like those for TOP2cc [14], cellular processing pathways should be similarly required for TOP1cc for exposing TOP1-hidden DNA breaks prior to the activation of CPT-induced DDR.

The CPT-induced comet tail moment and the reversibility of TOP1cc under RIP-and TIP-blocking conditions

The comet tail moment has been widely used to quantitatively represent the extent of DNA breakage in the comet assay [12, 13, 27], and a recent report has suggested that CPT induced the formation of comet tail moment in a transcription- and proteasome-dependent manner using the quiescent WI-38 cells [13]. Similarly, we have also found that both inhibition on transcription and proteasome-mediated proteolysis by the TIP-blocker DRB and LAC reduced the CPT-, but not the bleomycin (BLM)-induced comet tail moment, in the proliferating HCT116 cancer cells (Figure 3A). The replication inhibition by the RIP blocker APH has only little effect on both CPT- and BLM-induced comet tail moments (Figure $3 \mathrm{~A}$ ). It should be interesting to note here that $\mathrm{DRB}$ and $\mathrm{LAC}$, but not $\mathrm{APH}$, relieved the CPT-induced TOP1 downregulation (Figure 1E) [22]. The reversibility of CPT-induced DNA breaks under RIP- and TIP-blocking conditions was studied after $1 / 2-, 1-$ and $2 \mathrm{~h}$ of medium reversal, and all three processing inhibitors have little effect on the reversibility of the CPT-induced comet tail moment (Figure 3B).

TOP1cc induces ATM autophosphorylation $\left(\right.$ ATM $\left._{1981 p}\right)$, activation of its kinase activity and formation of ATM nuclear foci

Siu et al. [28] showed defects in activation of check- 
A

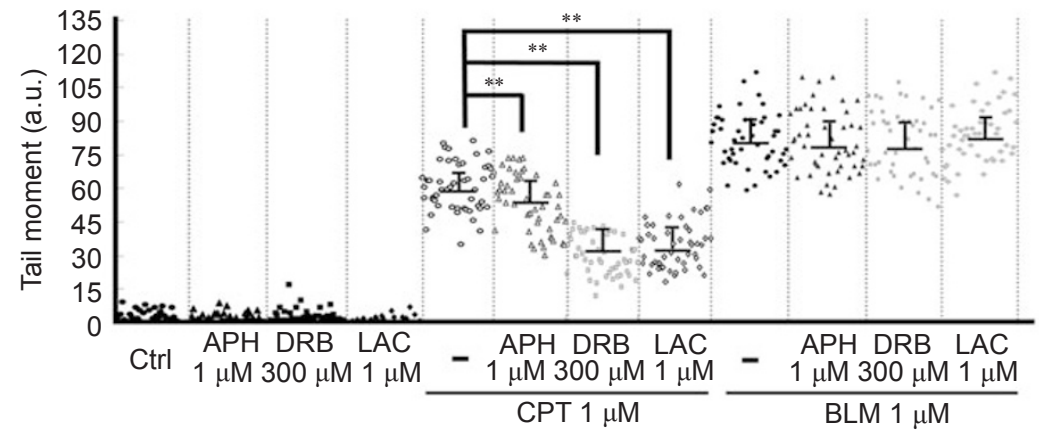

B

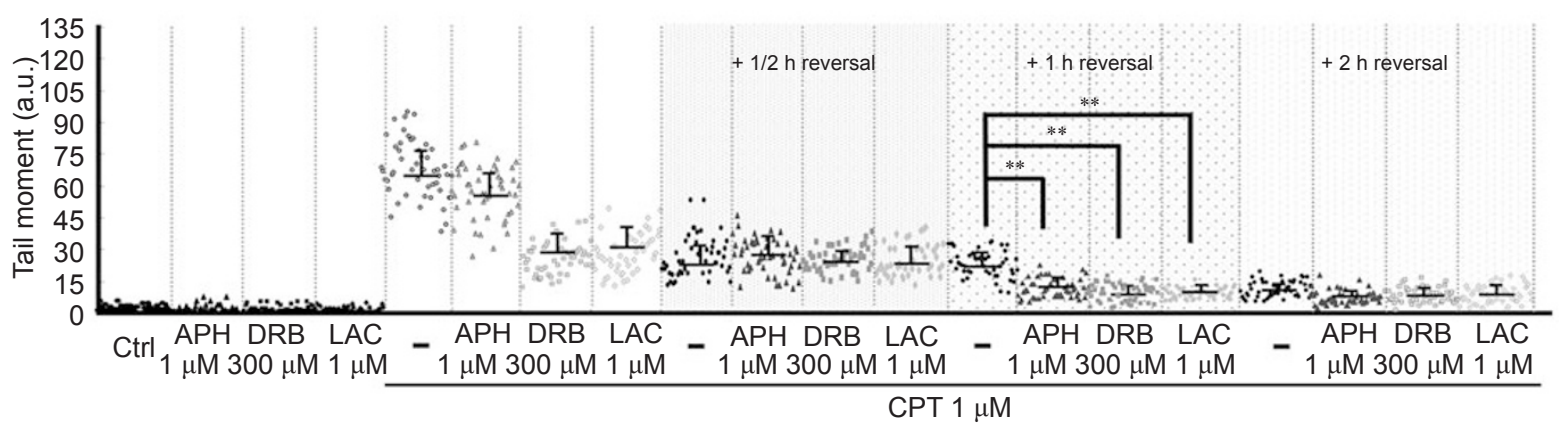

Figure 3 The CPT-induced comet tail moment under RIP- or TIP-blocking conditions. (A) Cotreatment of TIP blockers, but not the RIP blocker, caused a reduction in the CPT-induced comet tail moment. (B) The generation of CPT-induced comet tails under RIP- or TIP-blocking conditions is reversible. DRB and LAC were used as the TIP blockers and APH was used as the RIP blocker. Drug treatments, the comet assay and the reversibility assay were performed as described in Figure 1 . The lines indicate the mean values of the comet tail moment in different treatments. Asterisks $(* *, P<0.01)$ indicate the statistic difference.

point and CDK2 activity in Ataxia telangiectasia cells after long-term CPT treatment. Phosphorylation of ATM at Ser1981 $\left(\mathrm{ATM}_{1981 \mathrm{p}}\right)$ and its foci formation in response to CPT treatment has also been reported recently [2, 29]. Here, the immunofluorescence analysis (IFA) [29] was employed to determine whether CPT treatment induces the formation of ATM nuclear foci. As shown in Figure $4 \mathrm{~A}$, only a small portion $(\sim 10 \%)$ of untreated cells exhibited ATM foci, while $\sim 90 \%$ of HCT 116 cells treated with CPT $(10 \mu \mathrm{M} ; 2 \mathrm{~h})$ formed multiple nuclear foci. Using the Western blot assay, $\mathrm{ATM}_{1981 \mathrm{p}}$ was also observed after CPT treatment in a dose-dependent manner (Figure 4B). Using PHAS- 1 as the substrate, the ATM kinase activity of IR- or CPT-treated lysates was increased compared to that of untreated lysates (Figure 4C). Therefore, our results suggest that both kinase activity and ATM-associated pathways are activated on CPT treatment/TOP1cc formation.

Multiple repair and checkpoint pathways are activated after CPT treatment

To further characterize TOP1cc-mediated DDR, we examined the activation status of cellular factors involved in repair and checkpoint pathways after CPT treatment, and subsequently used them as the representative surrogate markers for various DDR activations. Consistent with activation of multiple DDR, CPT treatment caused the time- and dose-dependent phosphorylation of $\mathrm{p} 53$ at $\operatorname{Ser} 15\left(\mathrm{p} 53_{15 \mathrm{p}}\right.$ and its elevation in protein level), Chk2 at Thr68 $\left(\mathrm{Chk} 2_{68 \mathrm{p}}\right)$, RPA2 $\left(\mathrm{RPA}_{\mathrm{p}}\right)$ (Supplementary information, Figure S1B-S1D). In addition, we have also found that both phosphorylation of $\mathrm{H} 2 \mathrm{AX}(\gamma-\mathrm{H} 2 \mathrm{AX})$ and Chk1 at Ser345 $\left(\mathrm{Chk1}_{345 \mathrm{p}}\right)$ were stimulated in response to CPT treatment (Supplementary information, Figure $\mathrm{S} 1 \mathrm{E})[11-13,16]$. Using the elevated $\mathrm{p} 53$ protein level as an example, we showed that the CPT-induced DDR was similarly activated in two types of treatment protocols, the short-term treatment with higher CPT doses (1-20 $\mu \mathrm{M}$, Supplementary information, Figure S1B) and the long-term exposure with the clinically relevant doses (1-64 nM, Supplementary information, Figure S1C). Furthermore, our results showed that protein levels of Chk1 and Chk2 were not affected in the presence of CPT and/or other pharmacological inhibitors (Supplementary 
A

\begin{tabular}{cc}
$\mathrm{CPT}(\mu \mathrm{M})$ \\
\hline 0 & 10
\end{tabular}

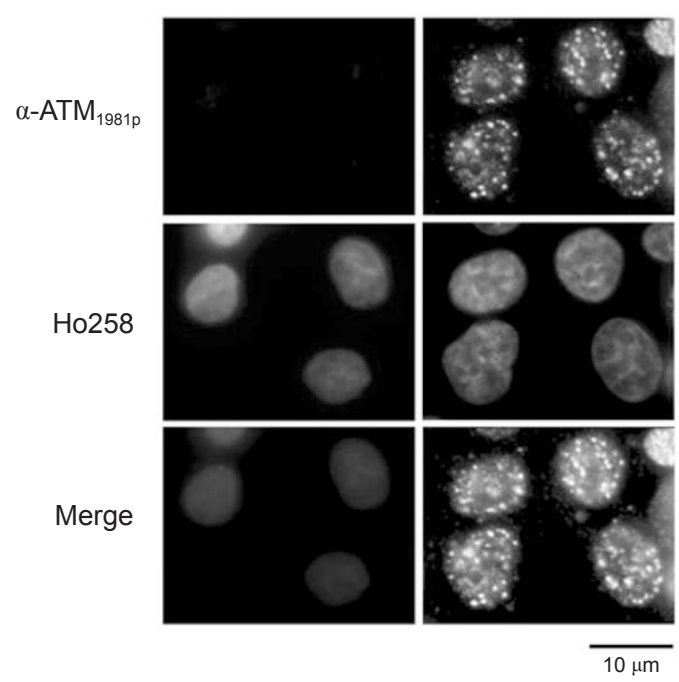

B

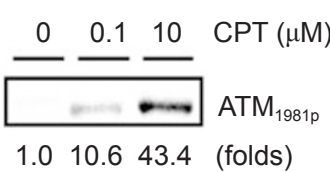

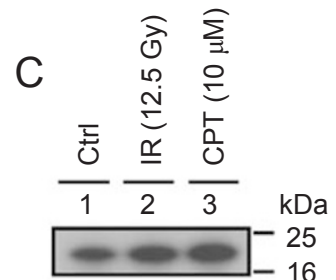

$\begin{array}{llll}1.0 & 3.6 & 2.2 & \text { (folds) }\end{array}$

Figure 4 CPT treatment induces the activation of ATM kinase. (A) Cellular exposure to CPT resulted in the formation of ATM foci. (B) CPT treatment caused a dose-dependent ATM autophosphorylation $\left(\mathrm{ATM}_{1981 \mathrm{p}}\right)$. HCT116 cells were treated with CPT $(0.1$ and/or $10 \mu \mathrm{M})$ for $2 \mathrm{~h}$, fixed, and subjected to both immunofluorescence analysis (IFA) and immunoblotting assay using anti-ATM 1981 antibodies. Nuclear DNA was stained with Hoechst dye. (C) The IR- and CPT-treated cellular extracts exhibited a higher ATM kinase activity. The kinase assay using PHAS-1 as substrate proteins for determining the activity of immunoprecipitated ATM proteins from different cell extracts was performed as described. $\alpha-\mathrm{ATM}_{1981 \mathrm{p}}$, IFA with anti-ATM ${ }_{1981 \mathrm{p}}$ antibody; Ho258, Hoechst dye 33258; merge, merged images from $\alpha$-ATM and Ho258; ctrl, control.

information, Figure S1F-S1G). Thus, cellular exposure to CPT (likely TOP1cc) results in DDR activation, and phosphorylation of signaling molecules examined here represents DDR activation, as opposed to the increase of overall amount of proteins.

Inhibition of transcription reduces $C P T$-induced AT$M_{198 I p}, p 53_{15 p}$ and $C h k 2_{68 p}$

In this section, we have explored the potential involve-

ment of TOP1cc-processing activities in the activation of CPT-induced DDR. We first investigated effect of transcription and/or replication inhibition, that is, blockage of TIP and/or RIP for TOP1cc, on CPT-activated DDR. In Figure 5A, our results showed that DRB treatment itself did not induce $\mathrm{ATM}_{1981 \mathrm{p}}$, but DRB cotreatment reduced the CPT-induced $\mathrm{ATM}_{1981 \mathrm{p}}$. This reduction effect on the CPT-activated $\mathrm{ATM}_{1981 \mathrm{p}}$ by DRB is likely mediated through its inhibitory activity on RNA transcription (the TIP pathway), since another transcription inhibitor $\alpha$-amanitin (40 $\mu \mathrm{M}$ pretreated for $1 \mathrm{~h}$; data not shown) also reduced the CPT-activated $\mathrm{ATM}_{1981 \mathrm{p}}$. In combination with our previous results using TOP2cc [14] and other reports $[11,13]$, these findings suggest that transcription collision participates in the TIP pathway and might

A

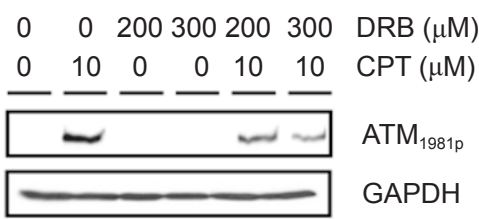

B
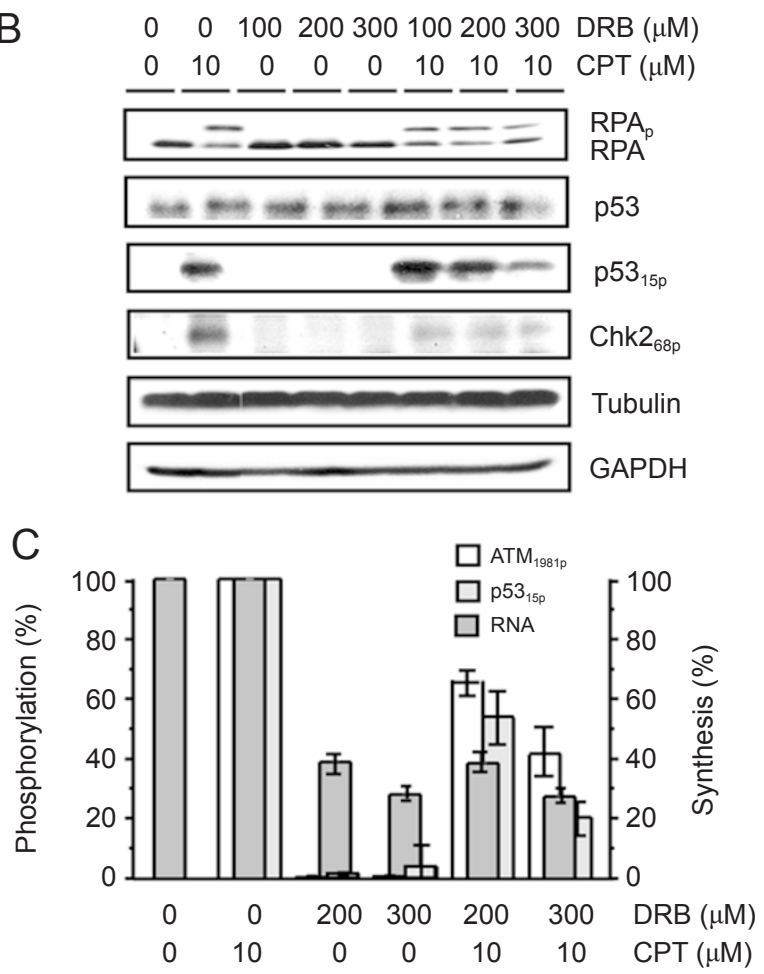

Figure 5 Distinctive effects of active replication and transcription on DDR activation induced by CPT. Transcription blockage affected greatly on CPT-induced ATM ${ }_{1981 \mathrm{p}}$ (A), p53 ${ }_{15 \mathrm{p}}$ and Chk2 $2_{68 \mathrm{p}}$ phosphorylation, but minimally on $\mathrm{RPA}_{p}$ phosphorylation (B). (C) The reductive effect of DRB on CPT-induced ATM ${ }_{1981 p}$ and p53 ${ }_{15 p}$ correlated with its level of transcription inhibition. 
contribute to the activation of CPT-induced ATM phosphorylation $\left(\mathrm{ATM}_{1981 \mathrm{p}}\right)$. This notion is further supported by the fact that CPT-induced p53 $3_{15 \mathrm{p}}$ and $\mathrm{Chk} 2_{68 \mathrm{p}}$, two known ATM-mediated phosphorylation events, were also reduced in the presence of DRB (Figure 5B). In Figure $5 \mathrm{C}$, quantitative analysis revealed that inhibitory levels of DRB on transcription (for example, $76.0 \pm 1.0 \%$ inhibition at $300 \mu \mathrm{M}$ ) were comparable to reductive extents of DRB on both CPT-activated $\mathrm{ATM}_{1981 \mathrm{p}}$ and p53 ${ }_{15 \mathrm{p}}$ (for example, $60.5 \pm 7.5 \%$ and $81.5 \pm 5.5 \%$ reduction at 300 $\mu \mathrm{M}$, respectively). Taken together, these results are consistent with the notion that the TIP pathway of TOP1cc contributes to the CPT-induced activation of ATM, p53 and Chk2 pathway. It should also be noted here that DRB treatment also resulted in an inhibition on DNA synthesis, although to a less extent than that of transcription inhibition (Supplementary information, Figure S1A). As shown later, inhibition of DNA synthesis has little effect on the CPT-induced activation of $\mathrm{ATM}_{1981 \mathrm{p}}, \mathrm{p} 53_{15 \mathrm{p}}$ and Chk $2_{68 p}$. Thus, the CPT-induced activation of $\mathrm{ATM}_{1981 \mathrm{p}}$, p5 $3_{15 \mathrm{p}}$ and $\mathrm{Chk} 2_{68 \mathrm{p}}$ are likely initiated by DNA lesions generated from the TIP-processed TOP1cc.

A

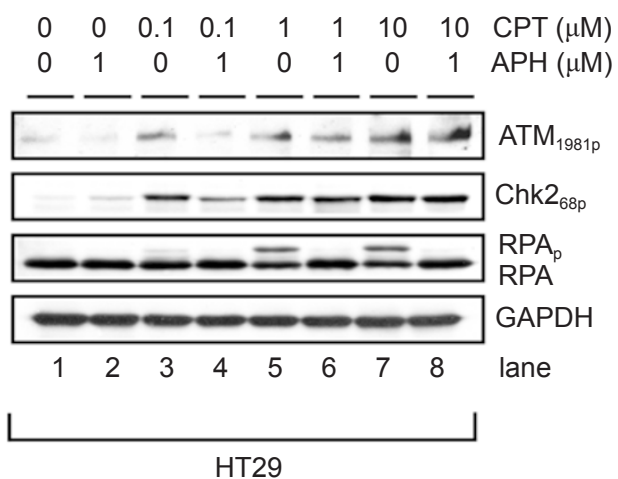

B

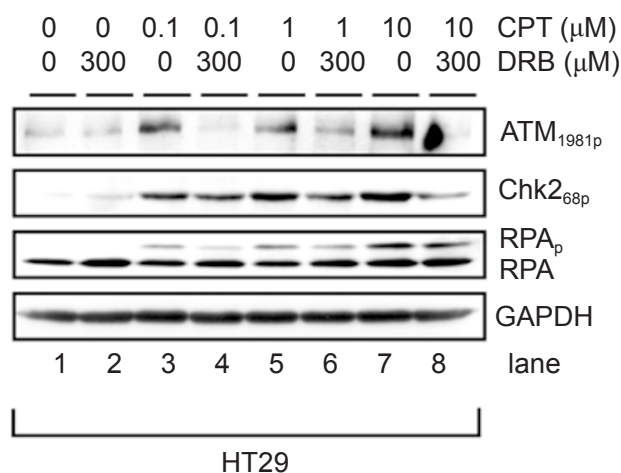

Both TIP- or RIP-processed TOPIcc caused activation of ATM, Chk2 and p53, while RPA2 activation is specifically induced by RIP

DNA lesions generated from the RIP-processed TOP1cc after replication collision are different from the TIP-processed ones generated after transcription collision [4]. We reasoned that these distinctive lesions from TIP- and RIP-processed TOP1cc should lead to distinct activation of corresponding DDR. As mentioned above, the RIP pathway of TOP1cc only contributes slightly to the activation of $\mathrm{ATM}_{1981 \mathrm{p}}, \mathrm{p} 53_{15 \mathrm{p}}$ and $\mathrm{Chk} 2_{68 \mathrm{p}}$. However, we have noticed in the literature that CPT treatment also caused a replication-dependent activation of $\mathrm{Chk} 2_{68 \mathrm{p}}$ in HT29 cells [16]. Differences in experimental approach, including cell lines (HT-29 vs HCT116) and CPT doses used ( 1 vs $10 \mu \mathrm{M})$, might account for the difference between our results and the published result of the $\mathrm{Chk} 2_{68 \mathrm{p}}{ }^{-}$ blocking effect by APH [16]. We further investigated whether the ATM-mediated DDR pathway is activated by TIP or RIP-processed TOP1cc and to resolve the above disparity, both HT29 and HCT116 cells, as well as different doses of CPT (0.1-10 $\mu \mathrm{M})$ were used. Our results

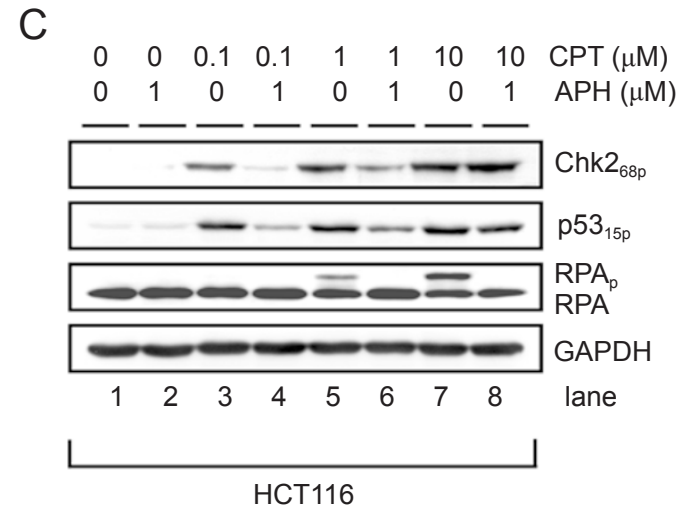

$\mathrm{D}$

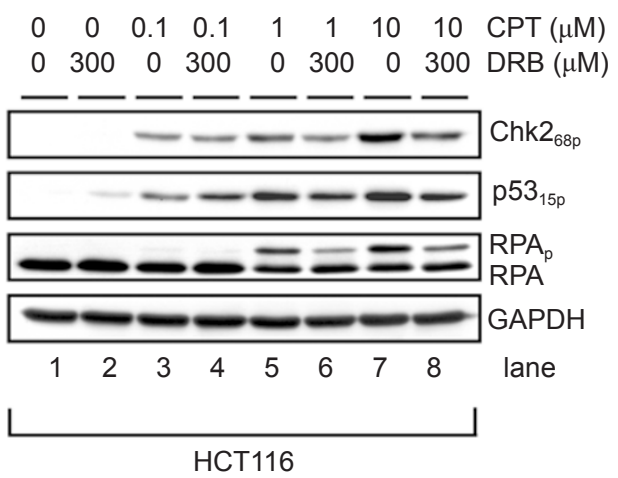

Figure 6 Differential involvements of TOP1cc-processing pathways in CPT-induced ATM, p53, Chk2 and RPA activation of cells treated with different CPT doses. Both exponentially growing HT29 (A-B) and HCT116 (C-D) colorectal cancer cells were treated with $1 \mu \mathrm{M} \mathrm{APH}(\mathbf{A}, \mathbf{C})$ or $300 \mu \mathrm{M}$ DRB (B, D) 30 min prior to and during CPT exposure (2 h) with indicated doses. 
A

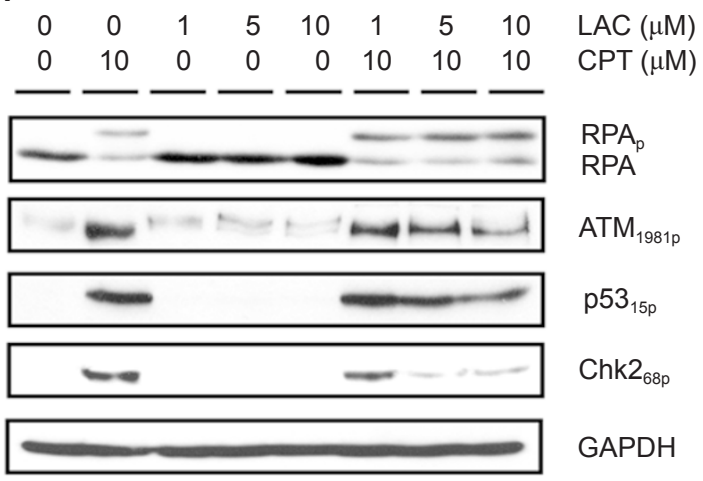

B

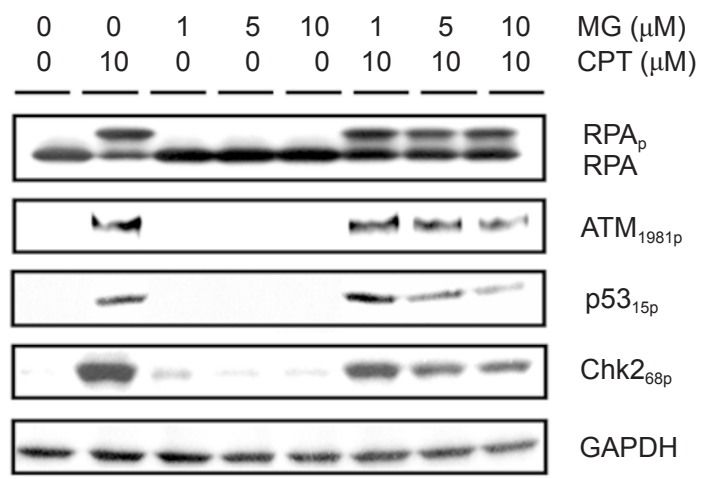

Figure 7 Proteolytic removal of TOP1 from TOP1cc by proteasome belongs to the TIP pathway. Proteasome inhibition by LAC (A) or MG (B) attenuated CPT-activated ATM $1981 \mathrm{p}, \mathrm{p} 53_{15 \mathrm{p}}$ and Chk2 ${ }_{68 \mathrm{p}}$, but not RPA2 ${ }_{\mathrm{p}}$. HCT116 cells were treated as described in Figure 5, except that proteasome inhibitors were used instead transcription inhibitor. LAC, lactacystin; MG, MG132.

showed that the RIP blocker APH completely abolished phosphorylation of RPA $\left(\mathrm{RPA}_{\mathrm{p}}\right)$, while DRB only had little effect on $\mathrm{RPA}_{\mathrm{p}}$ in all CPT-treated conditions (Figure 6). In addition, the CPT-activated $\gamma-\mathrm{H} 2 \mathrm{AX}$ was also greatly diminished in the presence of APH, despite that APH treatment alone also induced minor $\gamma$ - $\mathrm{H} 2 \mathrm{AX}$ activation (Supplementary information, Figure S2A). It should be noted here that the above given minor effect of DRB on $\mathrm{RPA}_{\mathrm{p}}$ is likely via its replication inhibitory activity (Supplementary information, Figure S1A) rather than transcription inhibition by DRB, since RPA $A_{p}$ induced by CPT was not affected in the presence of another transcription inhibitor $\alpha$-amanitin $(40 \mu \mathrm{M}$; data not shown). These results further supported the notion that the CPT-induced $\mathrm{RPA}_{\mathrm{p}}$ and possibly $\gamma$-H2AX were mainly initiated from the RIP-processed TOP1cc.

With CPT treatment at higher concentrations $(10 \mu \mathrm{M})$, $\mathrm{APH}$ has almost no effect on the CPT-activated $\mathrm{ATM}_{1981 \mathrm{p}}$, p53 $3_{15 \mathrm{p}}$ and $\mathrm{Chk} 2_{68 \mathrm{p}}$ (compare lanes 7 and 8 in Figure 6A6D). On the contrary, consistent with reported Chk2 results [16], APH could reduce $\mathrm{ATM}_{1981 \mathrm{p}}, \mathrm{Chk} 2_{68 \mathrm{p}}$ and p53 $3_{15 \mathrm{p}}$ when lower doses of CPT $(0.1$ and $1.0 \mu \mathrm{M})$ were used (Figure 6A and 6C). Interestingly, we have also found that DRB could not effectively reduce the CPTactivated $\mathrm{Chk} 2_{68 \mathrm{p}}$ and $\mathrm{p} 53_{15 \mathrm{p}}$ (but not $\mathrm{ATM}_{1981 \mathrm{p}}$ ) when lower doses of CPT $(0.1$ and $1 \mu \mathrm{M})$ were used (Figure $6 \mathrm{~B}$ and $6 \mathrm{D})$. Together, our results suggest that the activation mechanisms for low- $(0.1$ or $1 \mu \mathrm{M})$ or high-dose $(10$ $\mu \mathrm{M}) \mathrm{CPT}$-induced DDR might be different. In addition, we have also examined the CPT-induced $\mathrm{Chk}_{345 \mathrm{p}}$ under TIP- or RIP-blocking conditions. As shown in Supplementary information, Figure S2C, APH treatment alone induced a greater increase in $\mathrm{Chk}_{345 \mathrm{p}}$ than did $10 \mu \mathrm{M}$
CPT treatment. Cotreatment of the TIP-blocker DRB reduced the level of CPT-induced $\mathrm{Chk}_{345 \mathrm{p}}$ (Supplementary information, Figure S2C). Taken together, two notions were suggested by above observations (1) TIP and RIP pathway for TOP1cc are likely independent of each other regarding the activation of CPT-induced DDR; (2) multiple DDR pathways are differentially activated in response to different doses of CPT treatment.

\section{Proteolytic degradation of TOP1 contributes to activa- tion of CPT-induced DDR}

We sought to test whether proteasomal activity contributed to the TIP pathway, since both active transcription and ubiquitin/26S proteasome are critically involved in TOP1 downregulation on CPT treatment (Figure 2D) $[22,23]$. More importantly, our previous results showed that TOP2 downregulation belongs to the TIP pathway of TOP2cc [14]. As shown, proteasome inhibition by LAC (Figure 7A) or MG132 (MG, Figure 7B) affected the CPT-activated $\mathrm{ATM}_{1981 \mathrm{p}}, \mathrm{p} 53_{15 \mathrm{p}}$ and $\mathrm{Chk} 2_{68 \mathrm{p}}$ (TIP-mediated), but not RPA (RIP-mediated). For example, LAC treatment $(10 \mu \mathrm{M})$ reduced CPT-induced ATM $1981 \mathrm{p}, \mathrm{p} 53_{15 \mathrm{p}}$ and $\mathrm{Chk} 2_{68 \mathrm{p}}$ down to $\sim 40 \%, 56 \%$ and $33 \%$, respectively. In addition, the CPT-induced $\mathrm{Chk} 1_{345 \mathrm{p}}$ was also reduced in the presence of LAC (Supplementary information, Figure S2D). Further analysis of data revealed that the spectrum of TOP1cc-activated DDR (that is, ATM $_{1981}$, p5 $3_{15 \mathrm{p}}, \mathrm{Chk} 2_{68 \mathrm{p}}$ and $\mathrm{Chk} 1_{345 \mathrm{p}}$ ) attenuated by proteasome inhibitors was identical to those reduced by DRB (AT$\mathrm{M}_{1981 \mathrm{p}}, \mathrm{p} 53_{15 \mathrm{p}}, \mathrm{Chk} 2_{68 \mathrm{p}}$ and $\mathrm{Chk} 1_{345 \mathrm{p}}$ ). These results support the common role of transcription and proteasome in both TIP-associated proteolytic removal of TOP1 from TOP1cc and DDR activation. In addition, we showed 
that proteasome inhibition caused only stabilization of p53 [3] without that of concomitant p53 $3_{15 \mathrm{p}}$, and proteasome inhibitors had only minimal effect on protein levels of Chk1/2 and RPA (Supplementary information, Figure S1G). Our results are therefore most likely consistent with the notion that proteasome-mediated TOP1 downregulation in the TIP pathways for TOP1cc contributes directly to the CPT-activated DDR.

\section{CPT-induced and TIP-associated DDR activation is in-} dependent of DNA replication

In this section, we sought to investigate the relationship between TIP and RIP pathway of TOP1cc. First, a combination strategy with TIP and RIP pharmacological inhibitors was used. As shown in Figure 8A, either alone or in combination, $300 \mu \mathrm{M}$ of DRB ( $>70 \%$ of inhibition on transcription) and/or $1 \mu \mathrm{M}$ of APH ( $>90 \%$ of inhibition on transcription) did not induce any DDR activation that was examined. Most importantly, the TIP-blocker DRB could still efficiently reduce CPT-activated AT$\mathrm{M}_{1981 \mathrm{p}}, \mathrm{p} 53_{15 \mathrm{p}}$ and $\mathrm{Chk} 2_{68 \mathrm{p}}$ in the cellular status that over $90 \%$ of DNA synthesis was inhibited by the RIP blocker APH (compare lane 6 to 8; Figure 8A). These results thus not only supported that the TIP pathway of TOP1cc is independent of the RIP pathway but also suggested that DNA lesions generated from the TIP-processed TOP1cc are distinct from those generated from the RIP-processed ones.

We further studied the contribution(s) of replication, transcription and proteasome activity on the CPT-activated DDR in two lines of nonreplicating cells: the resting B cells isolated from mouse spleens and the serum-starved quiescent human MRC-5 primary cells. Serum starvation $(0.1 \%$ serum for $72 \mathrm{~h})$ not only drove MRC-5 cells into nonreplicating G0 quiescent phase but also caused a $15.5 \%$ reduction in TOP1 protein level (Figure 2C). Nevertheless, the CPT-induced TOP1 downregulation appeared to be efficient in both active proliferating and serum-starved MRC-5 cells, with latter being little more proficient (Figure 2C; lane 3: 47.2\% vs lane 6: 62.3\%; degraded after $4 \mathrm{~h}$ ). Consistently, the RIP-mediated RPA in response to CPT treatment was barely detectable in the serum-starved MRC-5 cells (Figure 8B). Moreover, CPT also caused a lower activation of ATM and Chk2 in the quiescent MRC-5 cells (compare lane 1 to 6; Figure $8 \mathrm{~B}$ ), which is likely owing to the lower TOP1 level. Both DRB and LAC effectively abolished the TIP-associated activation of $\mathrm{ATM}_{1981 \mathrm{p}}$ and $\mathrm{Chk} 2_{68 \mathrm{p}}$ on CPT treatment, while the RIP blocker APH had no effect in the quiescent MRC-5 cells (Figure 8B). Furthermore, the CPTactivated $\mathrm{ATM}_{1981 \mathrm{p}}$ also relied on both transcription- and proteasome-processing activities of TOP1cc in the rest-

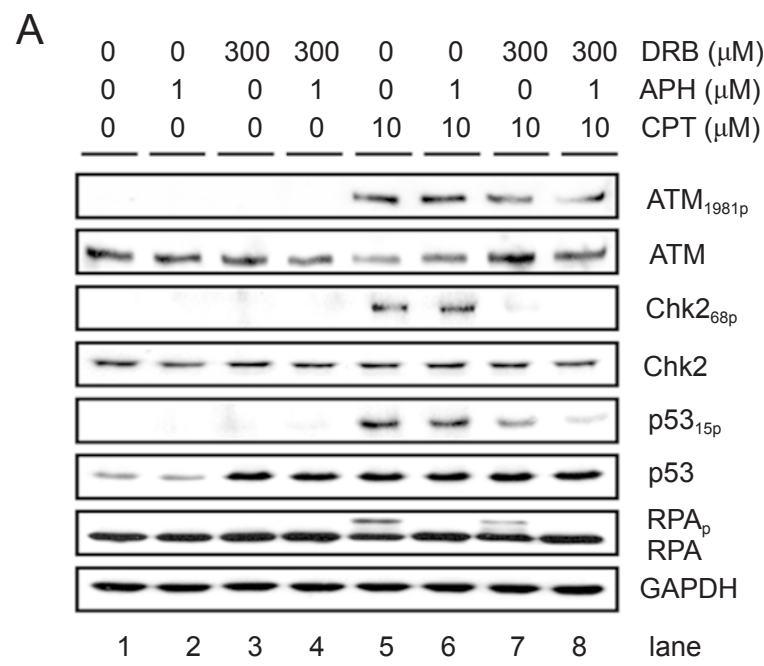

B

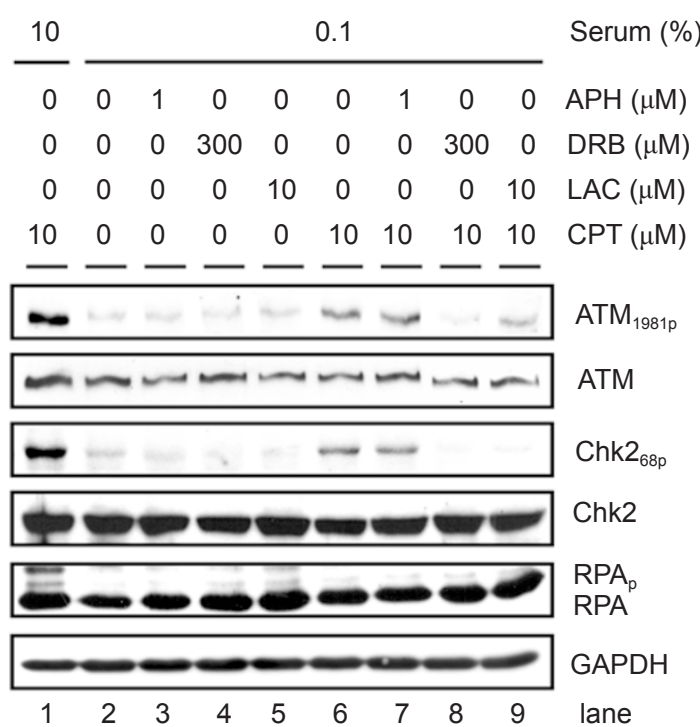

C

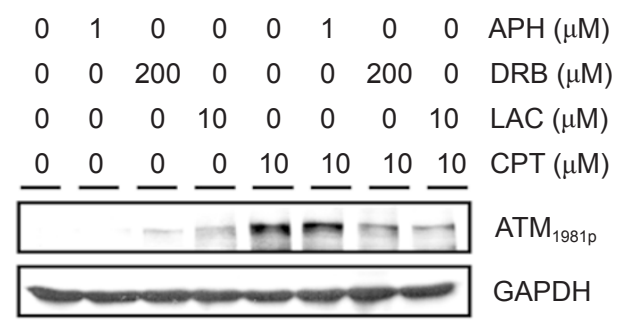

Figure 8 The TIP pathway for TOP1cc is independent of active DNA replication. (A) Effect of transcription inhibition on CPTinduced DDR activation in nonreplicating cells. HCT116 cells were pretreated with DRB and/or APH (dose as indicated) for $1 / 2 \mathrm{~h}$, followed by $2 \mathrm{~h}$ of CPT $(10 \mu \mathrm{M})$ cotreatment. The activation levels of CPT-activated DDR were examined by the immunoblotting assay with indicated antibodies. (B) Transcription or proteasome inhibition, but not replication blockage, affected CPT-induced DDR activation in quiescent MRC5 cells (C) The CPT-induced activation of ATM $_{1981 p}$ involved only transcriptional and proteasomal processing of TOP1cc in murine resting $B$ cells. 
ing B cells (Figure 8C).

RIP and TIP of DNA TOPIcc are required for formation of ATM and RPA foci, respectively

Here, CPT-induced formations of nuclear ATM- and/ or RPA-damaging foci were used to further dissect the distinct relationship between CPT-activated DDR and processing pathways of TOP1cc. As seen in Figure 9, treatments with processing inhibitors alone did not induce any increase in the formation of ATM or RPA foci in HCT116 cells, and CPT-induced formation of ATM foci $(\sim 90 \%$ of cells containing nuclear foci) was primarily blocked by the cotreatment of TIP-blocker DRB $(\sim 25 \%)$ or LAC $(\sim 20 \%)$. In contrast, the appearance of RIP-associated RPA foci ( $92 \%)$ was mainly affected by APH cotreatment ( $14 \%$; Figure $9 \mathrm{~B})$. Taken together, our results suggest that the TIP- and RIP-processed TOP1cc might be responsible for the CPT-induced ATM and RPA foci formation, respectively. Furthermore, these two processing pathways for TOP1cc are likely independent of each other and play distinctive roles in the activation of CPT-induced DDR.
TIP and RIP are specific for TOP1-linked DNA break

Next, we examined the specificity of processing pathways for topoisomerase-linked DNA breaks. As shown in Figure 10, IR (12.5 Gy) also induced DDR, including $\mathrm{ATM}_{1981 \mathrm{p}}, \mathrm{p} 53_{15 \mathrm{p}}$ and $\mathrm{Chk} 2_{68 \mathrm{p}}$. Importantly, IR-induced $\mathrm{ATM}_{1981 \mathrm{p}}, \mathrm{p} 53_{15 \mathrm{p}}$ and $\mathrm{Chk} 2_{68 \mathrm{p}}$ were not affected by the addition of processing blockers including DRB, MG132 and APH (Figure 10). Similar results were also obtained with treatment of a lower dosage of IR (1.25 Gy) (data not shown). Our results thereby suggest that both RIP and TIP pathways contribute to the initiation of CPTactivated DDR, but not to the activation of IR-induced DDR.

Pharmacological modulations on TIP and RIP resulted in differential protective effects on cell killing after low or high dose of CPT treatment

$\mathrm{CPT}$ has long been regarded as the S-phase-specific anticancer drug, and previous studies have also demonstrated that CPT-mediated cell death in cycling cells is dependent on DNA replication [4, 19, 30]. However, S-phase-independent cytotoxicity has been observed
B
A

$$
\text { 妾 }
$$
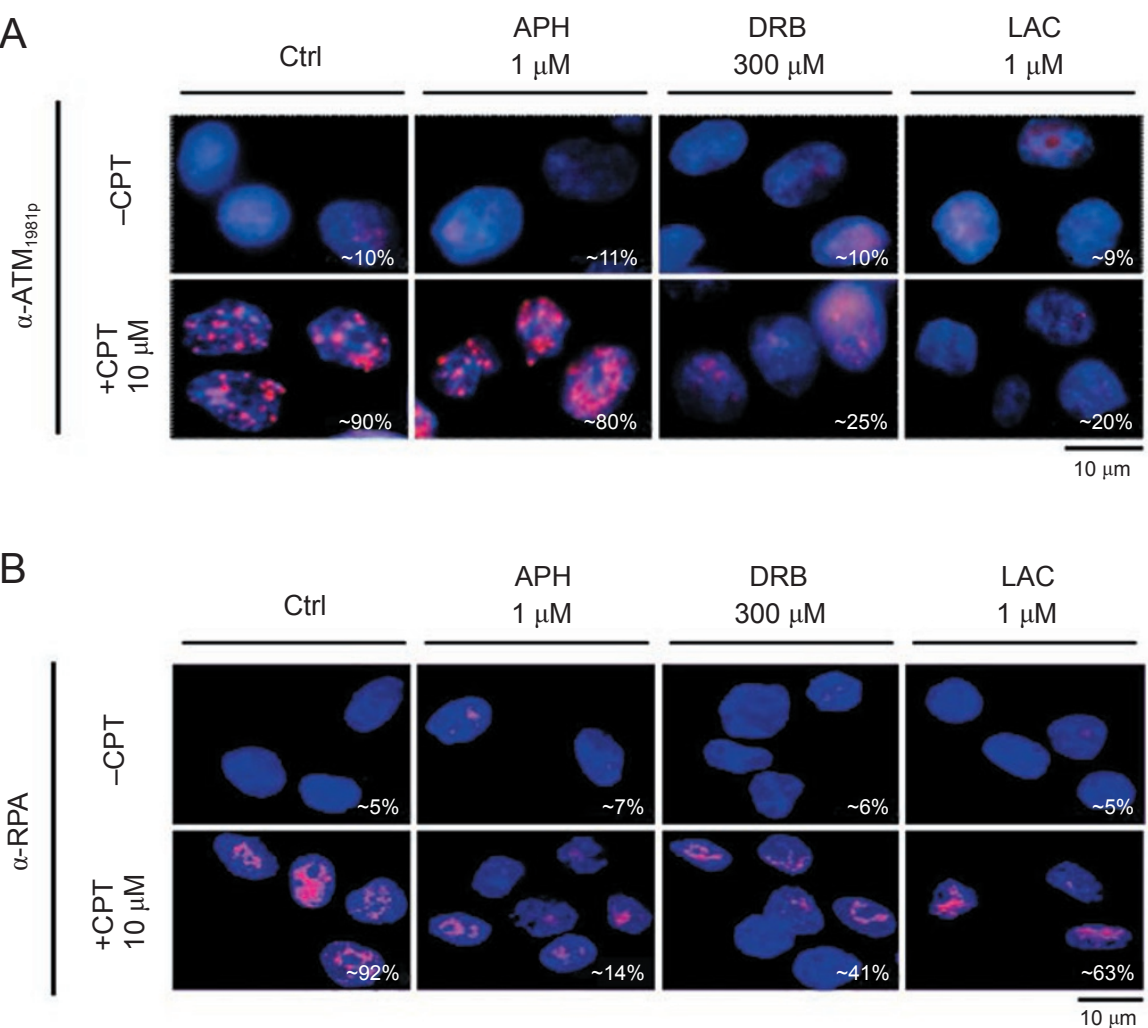

Figure 9 TIP and RIP pathways of TOP1Cc are distinctively required for CPT-induced formation of ATM and RPA foci. HCT116 cells were treated, followed by IFA, with either anti-ATM $1981 \mathrm{p}(\mathbf{A})$ or anti-RPA antibodies (B) as described. Merged images from $\alpha$-ATM (red, A) or $\alpha$-RPA (red, B) with Hoechst dye (blue, A-B) staining were shown. \%, the percentage of cells with clear foci. 
A
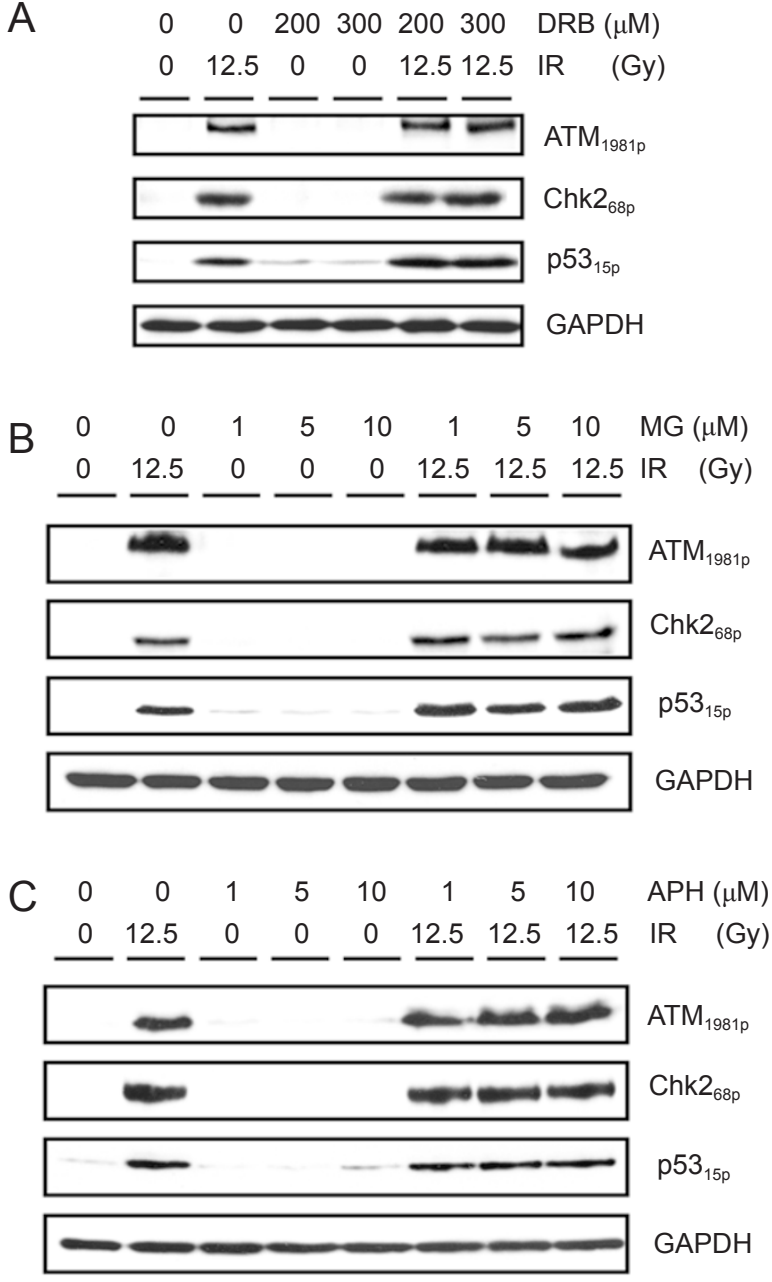

Figure 10 TIP and RIP activities are not involved in the DDR activation by IR-caused DNA breaks. Different inhibitors were used to examine effects of TIP, including transcription (A, DRB) or proteasome (B, MG), and RIP (C, APH) on IR-activated DDR. HCT116 cells were pretreated with different inhibitors for $1 / 2 \mathrm{~h}$ and then irradiated with $12.5 \mathrm{~Gy}$ IR. After additional $2 \mathrm{~h}$ of incubation, levels of DDR activation were examined as described.

with high doses of CPT treatment, and RNA synthesis inhibitor DRB prevents CPT-induced cell death in postmitotic neuronal cells [20]. In combination with our findings, these above results suggest that cellular processing activities, replication and transcription, could affect both TOP1cc-mediated DDR activation and cell killing. Therefore, we investigated the relationship between cellular processing pathways of TOP1cc and CPT-induced cell death using a clonogenic survival assay. As shown in Figure 11, CPT treatment caused cell killing dosedependently $(40.2 \pm 2.19 \%$ and $3.4 \pm 0.86 \%$ survival with $0.1 \mu \mathrm{M}$ and $10 \mu \mathrm{M}$ of CPT treatment, respectively). Modulations of TIP and RIP pathways reduced CPT- mediated cytotoxicity. Notably, the RIP blocker APH protected HCT116 cells from cell killing only when cells were exposed to low-dose CPT treatment $(0.1 \mu \mathrm{M})$. TIP blockers, DRB and LAC, have no effect on overall survival of cells treated with $0.1 \mu \mathrm{M}$ of CPT (Figure 11). Like the reduction effect of DRB and LAC on the TOP1cc-activated DDR (Figure 6), blockage of the TIP pathway by transcription or proteasome inhibition affect the cell viability under $10 \mu \mathrm{M}$ of CPT treatment much greater than that under $0.1 \mu \mathrm{M}$ of CPT treatment (Figure 11). Together, these results are consistent with the notion that RIP and TIP processing pathways play individual roles in the CPT-mediated differential signal transductions, which may then lead to different sensitivities in cancer cell killing by different dosages of CPT treatment.

\section{Discussion}

Cellular determinants for the activation of cellular responses to the protein-linked DNA damage have started to be revealed [12-15]. In this study, we have used the CPT-induced TOP1cc to study processing pathways involved in the DDR activation responding to TOP1-linked DNA breakage. A table summarizing our results in the quantitative manner is presented in Supplementary information, Table S1. Our results show that activation of a subset of CPT-induced DDR requires specific proteolytic removal of TOP1 from TOP1cc (TOP1 downregulation

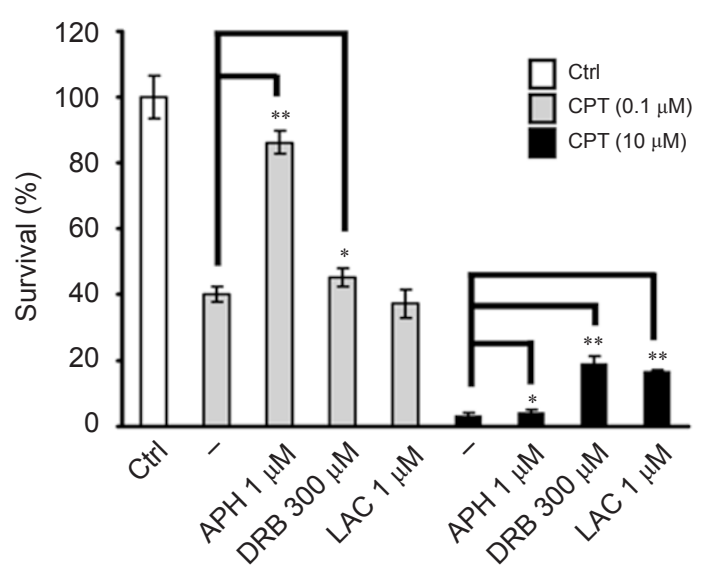

Figure 11 The differential contributions of TIP and RIP activities to CPT-induced cell killing at low and high dosages. HCT116 cells were pretreated with/without different processing inhibitors, including $A P H, D R B$ and $L A C$ for 30 min prior to exposure to 0.1 , 1.0 or $10 \mu \mathrm{M}$ CPT for another $2 \mathrm{~h}$ of cotreatment. The colony formation assay was then carried out to determine the overall cell survival. The error bars were calculated from two independent experiments of triplicate determinations. Asterisks $\left({ }^{*}, P<\right.$ $0.05 ; * *, P<0.01)$ indicate the statistic difference. 
by proteasome). Like those for TOP2cc [14], two mechanistically distinct TIP and RIP pathways for TOP1cc processing were identified. Consistent with the involvement of transcription and proteasomal degradation in CPTinduced TOP1 downregulation [22, 23], the inhibitory effects of transcription and proteasome blockers on the CPT-activated DDR (that is, $\mathrm{ATM}_{1981 \mathrm{p}}, \mathrm{p} 53_{15 \mathrm{p}}, \mathrm{Chk} 2_{68 \mathrm{P}}$ ) were reminiscent of each other. These data further support the notion that proteasomal degradation of TOP1 is one part of the TIP pathway. Based on our results and recent reports $[12,13]$, a requirement of processing activities for topoisomerase-linked DNA break should therefore be considered for the activation of its associated DDR, as well as downstream repair, recombination and cell death pathways.

\section{The activation of ATM kinase by the TIP-processed} TOPlcc

Three members of PIKK family, ATM, ATR and DNA-PK, play the central role in coordinating DDR [1-3]. Our data demonstrate that CPT treatment activates ATM kinase, while other studies showed that ATR and DNAPK also contribute to a subset of CPT-induced DDR $[21,31]$. Notably, our study revealed that the activation of CPT-induced ATM $_{1981 \mathrm{P}}$ relies on the TIP pathway of TOP1cc, while the CPT-activated RPAP requires the RIP pathway of TOP1cc. It has been reported that DNA-PK plays the major role in the CPT-activated RPAP [21]. Together, we propose that the CPT-induced TOP1cc could be processed by TIP and RIP pathways and generate various forms of DNA lesions. Subsequently, these TIP- and RIP-processed DNA lesions lead to the differential activation of ATM and DNA-PK kinase, respectively. In this regard, replication and transcription collision have been shown to convert the same TOP1cc into different forms of DNA lesion [4, 17, 18]. In addition, our results also suggest that, with different dosages of CPT treatment, the underlying activation mechanisms for CPT-induced DDR might be different. Specifically, our study demonstrates that CPT-induced $\mathrm{ATM}_{1981 \mathrm{p}}, \mathrm{p} 53_{15 \mathrm{p}}$ and $\mathrm{Chk} 2_{68 \mathrm{p}}$, as well as cell killing are greatly reduced by transcription or proteasome inhibition only in cells treated with high-dose CPT. Thus, it appears that the TIP pathway of TOP1cc plays a more important role in DDR induced by high-dose CPT, while the RIP pathway of TOP1cc plays a major role in DDR activated by low-dose CPT. Nevertheless, we have also showed a potential involvement of the RIP pathway in ATM activation induced by lower doses of CPT treatment, as reported [16]. In sum, the distinctive dependence of the processing pathways for TOP1cc-mediated $\mathrm{ATM}_{1981 \mathrm{p}}$ activation and cytotoxicity seems to be different and relies on the CPT doses used. This dose dependence might be explained by the dominant effect of DSBs from the RIP-processed TOP1cc during the low dose of CPT treatment. At higher doses of CPT treatment, DNA lesions generated from the TIP-processed TOP1cc (for example, accumulated SSBs) might be more abundant and thereby play a role in both cell killing and DDR activation. Furthermore, these results also support that the TIP and RIP pathway for TOP1cc are independent.

Interestingly, our study also shows that replication inhibition by APH also caused a major reduction in $\gamma-\mathrm{H} 2 \mathrm{AX}$ and RPA2p activation. It should also be noted that PIKK pathways exhibit certain degree of redundancy [1-3]. Therefore, it is plausible that different PIKK pathways could lead to similar activation of DDR depending on the nature of DNA lesions. Our results that both TIP and RIP pathway contribute to the CPT-induced elevation of p53 level support this notion.

\section{The cellular processing pathways of TOP1cc and impli- cations}

CPT cytotoxicity is generally thought to be primarily due to the S-phase-associated DSBs $[4,5,19]$. However, replication-independent CPT cell killing has also been observed [4, 5, 17, 20, 32]. In addition, transcription and proteasome inhibitor also modulated the cell-killing effect of CPT $[20,23]$. Thus, it is reasonable to speculate that S-phase-independent cytotoxicity of CPT may be elicited by the TIP pathway of TOP1cc. These results also suggest that cellular determinants for TOP1cc-mediated cell killing at different CPT dosages might be different. Our observations that the TIP pathway plays a replication-independent role in the TOP1cc-induced DDR activation, as well as in the cell killing with high-dose CPT treatment, are consistent with the above notions. In addition, the fact that modulations of RIP and TIP pathway respectively reducing TOP1cc-induced cell death at high- and low-dose CPT treatments, positively correlated with their attenuation effects on activation of ATM pathways on exposure to different CPT dosages, suggests a relationship between ATM kinase and TOP1cc-mediated cell killing.

The UPP plays important roles in regulating various aspects of cellular activities and thereby also provides a potential target for chemotherapy [4-6, 33]. In our study, we have shown that proteasome-mediated TOP1 downregulation is one part of the TIP pathway possibly downstream of transcription collision between RNA polymerase and TOP1cc. Interestingly, Bortezomib, the first proteasome inhibitor tested in clinical trial, has the greatest efficacy when combined with other chemotherapeutic agents including the TOP1-targeting drug irinotecan at its low dosage $[33,34]$. Consistently, we have also 
reported that the proteasome inhibitor MG132 sensitized cells to CPT-induced cytotoxicity and apoptosis [23]. Combined with our current study, we therefore argue that pharmacological interventions altering the half-life of topoisomerases may improve therapeutic potential when topoisomerase-targeting drugs are used at lower clinical doses. The high-dose treatment should not be combined with the TIP blockers. Our recent study on the contribution of TIP and RIP pathway to etoposide-induced cell death and NHEJ repair also supports this notion.

In summary, our present results demonstrate that protein-capped DNA damage (for example, TOP1cc) requires specific cellular processing activities to expose DNA lesions for the initial DNA damage detection, followed by activation of corresponding downstream DDR. As a result, blockages of DNA lesions generated from either the TIP- or RIP-processed TOP1cc modulate the downstream CPT-inducted DDR activation and cell killing. Therefore, tempering of TIP and/or RIP pathways should present a novel intervention strategy for enhancing sensitivity of cancer cells to and/or preventing clinical side effects exhibited by topoisomerase-targeting therapeutic drugs.

\section{Materials and Methods}

\section{Chemicals, drugs and cell culture}

Reagents were obtained from Sigma-Aldrich Inc unless stated otherwise. MG132 (carbobenzoxy-1-leucyl-1-leucyl-1-leucinal), LAC and DRB were from Calbiochem Inc. HCT116 colorectal, BT474 breast cancer cell lines, MRC-5 primary fibroblasts and murine resting B cells were generously provided by Drs WB Wang and SC Miaw (College of Medicine, National Taiwan University). The ZR75-1 breast cancer cell line was purchased from Bioresource Collection and Research Center (Hsinchu). Cells were grown in a $37{ }^{\circ} \mathrm{C}$ incubator with $5 \% \mathrm{CO}_{2}$ in DMEM media supplemented with $10 \%$ fetal bovine serum, l-glutamine $(2 \mathrm{mM})$, penicillin $(100 \mathrm{U} / \mathrm{ml})$ and streptomycin $(100 \mu \mathrm{g} / \mathrm{ml})$.

\section{Antibodies and the immunoblotting analysis}

Antibodies specifically against p53, anti-p53 phospho (Ser15), anti-Chk2 and anti-Chk2 phospho (Thr68) were purchased from Cell Signaling Inc. Anti-cdc2 phospho (Tyr15) and anti-tubulin antibodies were from Santa Cruz Biotechnology Inc. Anti-RPA, anti-ATM phospho (Ser1981) and anti-GAPDH antibodies were obtained from Upstate, Oncogene Research Products and Cayman Chemical, respectively. The immunoblotting analysis was done as described previously [23] with slight modifications. Briefly, drug-treated cells were washed once with an ice-cold $1 \times$ PBS buffer. Cell lysis was achieved by addition of RIPA buffer $(150 \mathrm{mM}$ $\mathrm{NaCl}, 10 \mathrm{mM}$ Tris ( $\mathrm{pH} 7.2), 1 \%$ Deoxycholate, $1.0 \%$ TritonX$100,0.1 \%$ SDS and $5 \mathrm{mM}$ EDTA) with freshly added protease inhibitors (Roche). Proteins in the supernatants of lysates ( $\sim 50 \mu \mathrm{g}$ of proteins) were mixed with equal volume of $2 \times$ SDS sample buffer, boiled for $5 \mathrm{~min}$, then electrophoretically separated by SDS-PAGE and then transferred to nitrocellulose paper. Immunoblotting analyses were carried out with specific antibodies via enhanced chemiluminescence procedure.

\section{The ATM kinase activity assay}

Immunoprecipated (IPed) ATM kinase assays were essentially carried out as described [35]. The cell lysis was achieved by ATM lysis buffer (ALB; $20 \mathrm{mM}$ HEPES (pH 7.4), $150 \mathrm{mM} \mathrm{NaCl}, 1.5$ $\mathrm{mM} \mathrm{MgCl} 2,0.2 \%$ Tween 20, $1 \mathrm{mM}$ EDTA, $1 \mathrm{mM}$ DTT, $20 \mathrm{mM}$ glycerophosphate, $10 \mathrm{mM} \mathrm{NaF}, 0.2 \mathrm{mM} \mathrm{Na}_{3} \mathrm{VO}_{4}$ and protease inhibitor cocktail) and protein amounts in cell lysates were assayed by the standard Bradford protein assay using BSA as standard. ATM proteins were precipitated with anti-ATM antibody (Ab-3, Oncogene Research Products) and protein A/G Sepharose beads (Amersham Inc). Specifically, $0.5 \mathrm{mg}$ of total proteins and $4 \mu \mathrm{l}$ of anti-ATM were combined for each IP reaction, and then incubated overnight at $4{ }^{\circ} \mathrm{C}$ with gentle rotation. Immunoprecipitates were washed twice with ALB, once with high-salt buffer (HSB, $0.1 \mathrm{M}$ Tris- $\mathrm{HCl}(\mathrm{pH} 7.4), 0.6 \mathrm{M} \mathrm{NaCl})$, and twice with ATM kinase buffer (10 mM HEPES (pH 7.2), $25 \mathrm{mM} \mathrm{KCl}, 10 \mathrm{mM} \mathrm{NaCl}, 1.1 \mathrm{mM}$ $\mathrm{MgCl}_{2}, 0.1 \mathrm{mM}$ EDTA, $0.1 \mathrm{mM}$ DTT and $10 \mathrm{mM}$ cold ATP). For the kinase assay, two-third of the immunoprecipitates was incubated with $1 \mu \mathrm{g}$ of PHAS-1 proteins in kinase buffer with $5 \mu \mathrm{Ci}$ of $32 \mathrm{P}-\gamma$-ATP at $30{ }^{\circ} \mathrm{C}$ for $60 \mathrm{~min}$. Proteins were then resolved by $5 \%$ SDS-PAGE. After electrophoresis, gels were dried and autoradiographed with X-ray films. Subsequent quantitative analysis was carried out by a phosphoimager (Molecular Dynamics Inc). The remaining one-third of the immunoprecipitates was used as protein loading control using the western blot technique with anti-ATM antibodies.

Experimental assays for TOP1-linked DNA breaks (TOP1cc) The TOP1 trapping assay A total of $2 \times 10^{5}$ cells were pre-seeded overnight in a 12 -well plates before drug treatments. After treatments (for example, CPT $10 \mu \mathrm{M}, 30$ min for TOP1 trapping), cells were harvested, followed by immediately lysis with RIPA buffer. Protein quantization and immunoblotting analyses were performed as described [14].

The ICE assay The ICE assay was used to differentiate free TOP1 from DNA-linked TOP1cc with $\mathrm{CsCl}$ gradient $[14,24]$. Pre-seeded HCT116 cells $\left(1.5 \times 10^{6}\right.$ in a $60-\mathrm{mm}$ dish $)$ were treated with different drugs for either $30 \mathrm{~min}$ (to examine TOP1cc formation) or $4 \mathrm{~h}$ (to examine degradation of TOP1) and lysis was achieved by addition of $1 \mathrm{ml}$ of STE buffer (1\% sarkosyl, $10 \mathrm{mM}$ Tris- $\mathrm{HCl}(\mathrm{pH}$ 8.0), $1 \mathrm{mM}$ EDTA). Collected lysates were then fractionated in $\mathrm{CsCl}$ gradient and factions were collected as described [14]. For most experiments, aliquots $(50 \mu \mathrm{l})$ of fractions were diluted with $100 \mu \mathrm{l}$ of SP buffer ( $25 \mathrm{mM}$ sodium phosphate $(\mathrm{pH} 6.5))$ and the diluted mixtures were then applied onto a pre-soaked Hybond $\mathrm{C}$ nitrocellulose membrane (SP buffer, $1 / 2 \mathrm{~h}$ ) using a dot-blot apparatus (BioRad). The membranes were washed with SP buffer once and then immunoblotted.

The comet assay for TOP1-mediated DNA breaks CPT-treated cells were pelleted and resuspended in ice-cold $1 \times$ PBS. The comet assay $[12,13,27]$ was used to analyze the integrity of chromosome DNA. Comet images were visualized and captured at $\times 400$ magnifications with the Nikon Eclipse 80 i fluorescence microscope equipped with a CCD camera (DS-Ri1, Nikon). 
The medium reversal experiment for TOP1cc The highly reversible nature of TOP1-mediated DNA breakage is one of the unique characteristics for TOP1cc [4]. The standard medium reversal experiments by an additional incubation with drug-free medium were performed as described [27]. Typically, the drugtreated cells were washed twice, and then incubated in the drugfree medium for additional $30 \mathrm{~min}$, at $37{ }^{\circ} \mathrm{C}$ in a $\mathrm{CO}_{2}$ incubator before TOP1cc assays were performed.

The TOP1 downregulation assay CPT-induced degradation of TOP1cc was similarly performed as reported [14, 27]. Briefly, 2 $\times 10^{5}$ cells were treated with $10 \mu \mathrm{M}$ CPT for 2-6 h, washed once and replenished with fresh media, then cultured for an additional $30 \mathrm{~min}$. Cells were lysed with $50 \mu \mathrm{l}$ of alkali lysis buffer $(200 \mathrm{mM}$ $\mathrm{NaOH}, 2 \mathrm{mM}$ EDTA), and $8 \mu \mathrm{l}$ of neutralizing buffer $(1 \mathrm{M} \mathrm{HCl}$, $600 \mathrm{mM}$ Tris $(\mathrm{pH} \mathrm{8.0)})$ for neutralization. For the S7 nuclease digestion, $6.6 \mu \mathrm{l}$ of a $10 \times \mathrm{S} 7$ nuclease reaction buffer $(50 \mathrm{mM}$ $\mathrm{MgCl}_{2}, 50 \mathrm{mM} \mathrm{CaCl}, 5 \mathrm{mM}$ dithiothreitol, $1 \mathrm{mM}$ EDTA, 10× protease inhibitor cocktail) and staphylococcal S7 nuclease (60 U; Roche) were added to neutralization mixtures with a 20-min digestion on ice.

\section{The immunofluorescence analysis}

HCT116 cells were plated onto cover slips (pre-coated with FBS) 1 day before drug treatments. After being treated with different drugs for $2 \mathrm{~h}$, cells were washed with $1 \times$ PBS once and followed by fixation with $3 \%$ paraformaledehyde plus $2 \%$ sucrose in $1 \times$ PBS for $10 \mathrm{~min}$ at room temperature. Cells were washed with $1 \times$ PBS, permeated by buffer A (20 mM HEPES, $50 \mathrm{mM} \mathrm{NaCl}, 3$ $\mathrm{mM} \mathrm{MgCl} 2,300 \mathrm{mM}$ sucrose and $0.5 \%$ Triton X-100) for $10 \mathrm{~min}$ incubation at room temperature and then blocked in buffer B $(2 \%$ FBS and $0.05 \%$ Tween-20 in PBS) for $1 \mathrm{~h}$. Anti-ATM ${ }_{1981 \mathrm{p}}$ antibodies were added for another $16 \mathrm{~h}$ of incubation at $4{ }^{\circ} \mathrm{C}$. After threetime washes with $1 \times$ PBS, cells were incubated with Rhodamineconjugated secondary antibody (Molecular Probe) and $0.5 \mathrm{mg} /$ $\mathrm{ml}$ Hoechst 33258 at $37{ }^{\circ} \mathrm{C}$ for another $1 \mathrm{~h}$. Cover slips were then washed with $1 \times$ PBS three times and finally mounted with Fluoromount-G (Douthern Biotech Associates). Over 50 cells were scored and the percentage of foci-positive cells was calculated.

\section{The cytotoxicity assay - the colony formation assay}

The colony formation assay was performed to analyze the cell cologenic growth ability. Sub-confluence cells were treated with drugs as described previously. After drug treatments, $3 \times 10^{2-3}$ cells were reseeded to a $6-\mathrm{cm}$ culture dish with subsequent growth in drug-free medium. After 10 days, colonies were fixed with methanol and stained with $0.1 \%$ crystal violet. The cologenic viability relative to untreated control was scored.

\section{Quantitative measurement and statistic analysis}

The immunoblotting results were scanned and the band intensities of individual lanes were then analyzed with ImageQuant software following manufacture's protocol. Data were normalized against the levels of loading controls (that is, GAPDH or tubulin). For the Comet assay, over several hundred cells were typically scored to calculate the overall percentage (\%) of cells with comet tails. For the measurement of comet tail moment, at least 50 cells in each treatment were analyzed for their tail moment by the CometScore software following the recommended protocol. For the
ATM kinase activity, the autoradiography of $\gamma-{ }^{32} \mathrm{P}$-labelled PHAS1 was determined by a phosphoimager (Molecular Dynamics) and normalized against the amounts of IPed proteins. Quantitative results were further analyzed and graphed using KaleidaGraph 3.5 (Synergy Software) or Microsoft Excel. In general, the levels of activated signaling molecules in untreated controls and CPTtreated samples were taken as $0 \%$ and $100 \%$, respectively. Data analyses of cell viability were performed with the uni-polar, paired Student $t$-test. Data were considered statistically significant and very significant when $P$-values were less than 0.05 (marked as *) and $0.01(* *)$, respectively.

\section{Acknowledgments}

We are grateful for the cell lines provided by Drs Won-Bo Wang and Shi-Chuen Miaw (National Taiwan University). We also thank Drs Carmela Palermo (Columbia University), Shu-Chun Teng and Fan-Lu Kung (National Taiwan University) for critical reading of the paper and their comments. This work was supported by grants from the National Science Council (NSC95-2320-B002-097-MY3, 96-2320-B-002-081-MY3) and the National Health Research Institute (NHRI-EX97-9523BI).

\section{Reference}

1 Zhou BB, Bartek J. Targeting the checkpoint kinases: chemosensitization versus chemoprotection. Nat Rev Cancer 2004; 4:216-225.

2 Falck J, Coates J, Jackson SP. Conserved modes of recruitment of ATM, ATR and DNA-PKcs to sites of DNA damage. Nature 2005; 434:605-611.

3 Sancar A, Lindsey-Boltz LA, Unsal-Kacmaz K, Linn S. Molecular mechanisms of mammalian DNA repair and the DNA damage checkpoints. Annu Rev Biochem 2004; 73:39-85.

4 Li TK, Liu LF. Tumor cell death induced by topoisomerasetargeting drugs. Annu Rev Pharmacol Toxicol 2001; 41:53-77.

5 Pommier Y. Topoisomerase I inhibitors: camptothecins and beyond. Nat Rev Cancer 2006; 6:789-802.

6 Nitiss JL. Targeting DNA topoisomerase II in cancer chemotherapy. Nat Rev Cancer 2009; 9:338-350.

7 Connelly JC, Leach DR. Repair of DNA covalently linked to protein. Mol Cell 2004; 13:307-316.

8 Staker BL, Hjerrild K, Feese MD, et al. The mechanism of topoisomerase I poisoning by a camptothecin analog. Proc Natl Acad Sci USA 2002; 99:15387-15392.

9 Stewart L, Redinbo MR, Qiu X, Hol WG, Champoux JJ. A model for the mechanism of human topoisomerase I. Science 1998; 279:1534-1541.

10 Redinbo MR, Stewart L, Kuhn P, Champoux JJ, Hol WG. Crystal structures of human topoisomerase I in covalent and noncovalent complexes with DNA. Science 1998; 279:15041513.

11 Sordet O, Redon CE, Guirouilh-Barbat J, et al. Ataxia telangiectasia mutated activation by transcription- and topoisomerase I-induced DNA double-strand breaks. EMBO Rep 2009; 10:887-893.

12 Lin CP, Ban Y, Lyu YL, Liu LF. Proteasome-dependent processing of topoisomerase I-DNA adducts into DNA double 
strand breaks at arrested replication forks. J Biol Chem 2009; 284:28084-28092.

13 Lin CP, Ban Y, Lyu YL, Desai SD, Liu LF. A ubiquitinproteasome pathway for the repair of topoisomerase I-DNA covalent complexes. $J$ Biol Chem 2008; 283:21074-21083.

14 Fan JR, Peng AL, Chen HC, et al. Cellular processing pathways contribute to the activation of etoposide-induced DNA damage responses. DNA Repair (Amst) 2008; 7:452-463.

15 Zhang A, Lyu YL, Lin CP, et al. A protease pathway for the repair of topoisomerase II-DNA covalent complexes. $J$ Biol Chem 2006; 281:35997-36003.

16 Takemura H, Rao VA, Sordet O, et al. Defective Mre11dependent activation of Chk2 by ataxia telangiectasia mutated in colorectal carcinoma cells in response to replicationdependent DNA double strand breaks. J Biol Chem 2006; 281:30814-30823.

17 Wu JX, Liu LF. Processing of topoisomerase I cleavable complexes into DNA damage by transcription. Nucleic Acids Res 1997; 25:4181-4186.

18 Tsao YP, Russo A, Nyamuswa G, Silber R, Liu LF. Interaction between replication forks and topoisomerase-I-DNA cleavable complexes - studies in a cell-free Sv40 DNA-replication system. Cancer Res 1993; 53:5908-5914.

19 Hsiang YH, Lihou MG, Liu LF. Arrest of replication forks by drug-stabilized topoisomerase i-dna cleavable complexes as a mechanism of cell killing by camptothecin. Cancer Res 1989; 49:5077-5082.

20 Morris EJ, Geller HM. Induction of neuronal apoptosis by camptothecin, an inhibitor of DNA topoisomerase-I: evidence for cell cycle-independent toxicity. J Cell Biol 1996; 134:757770.

21 Shao RG, Cao CX, Zhang HL, et al. Replication-mediated DNA damage by camptothecin induces phosphorylation of RPA by DNA-dependent protein kinase and dissociates RPA: DNA-PK complexes. EMBO J 1999; 18:1397-1406.

22 Desai SD, Zhang H, Rodriguez-Bauman A, et al. Transcription-dependent degradation of topoisomerase I-DNA covalent complexes. Mol Cel Biol 2003; 23:2341-2350.

23 Desai SD, Li TK, Rodriguez-Bauman A, Rubin EH, Liu LF. Ubiquitin/26S proteasome-mediated degradation of topoi- somerase I as a resistance mechanism to camptothecin in tumor cells. Cancer Res 2001; 61:5926-5932.

24 Daroui P, Desai SD, Li TK, Liu AA, Liu LF. Hydrogen peroxide induces topoisomerase I-mediated DNA damage and cell death. J Biol Chem 2004; 279:14587-14594.

25 Subramanian D, Kraut E, Staubus A, Young DC, Muller MT. Analysis of topoisomerase I/DNA complexes in patients administered topotecan. Cancer Res 1995; 55:2097-2103.

26 Afshari CA, Barrett JC. Disruption of G0-G1 arrest in quiescent and senescent cells treated with phosphatase inhibitors. Cancer Res 1994; 54:2317-2321.

27 Li TK, Houghton PJ, Desai SD, et al. Characterization of ARC-111 as a novel topoisomerase I-targeting anticancer drug. Cancer Res 2003; 63:8400-8407.

28 Siu WY, Lau A, Arooz T, et al. Topoisomerase poisons differentially activate DNA damage checkpoints through ataxiatelangiectasia mutated-dependent and -independent mechanisms. Mol Cancer Ther 2004; 3:621-632.

29 Bakkenist CJ, Kastan MB. DNA damage activates ATM through intermolecular autophosphorylation and dimer dissociation. Nature 2003; 421:499-506.

30 D'Arpa P, Beardmore C, Liu LF. Involvement of nucleic acid synthesis in cell killing mechanisms of topoisomerase poisons. Cancer Res 1990; 50:6919-6924.

31 Furuta T, Takemura H, Liao ZY, et al. Phosphorylation of histone H2AX and activation of Mre11, Rad50, and Nbs1 in response to replication-dependent DNA double-strand breaks induced by mammalian DNA topoisomerase I cleavage complexes. J Biol Chem 2003; 278:20303-20312.

32 Liu LF, Desai SD, Li TK, Mao Y, Sun M, Sim SP. Mechanism of action of camptothecin. Ann N Y Acad Sci 2000; 922:1-10.

33 Adams J. The development of proteasome inhibitors as anticancer drugs. Cancer Cell 2004; 5:417-421.

$34 \mathrm{Xu}$ Y, Villalona-Calero MA. Irinotecan: mechanisms of tumor resistance and novel strategies for modulating its activity. Ann Oncol 2002; 13:1841-1851.

35 Canman CE, Lim DS, Cimprich KA, et al. Activation of the ATM kinase by ionizing radiation and phosphorylation of p53. Science 1998; 281:1677-1679.

(Supplementary information is linked to the online version of the paper on Cell Research website.) 